\title{
THE ECOLOGY OF DISTANCE LEARNING: BRIDGING THE GAP BETWEEN UNIVERSITY AND STUDENT
}

\author{
M.P. van Niekerk* \\ College of Education \\ e-mail: Vniekmp@unisa.ac.za
}

\section{Schmidt*}

College of Education

e-mail: schmil@unisa.ac.za

*University of South Africa

Pretoria, South Africa

\section{ABSTRACT}

Bridging the gap between the university and the student in distance learning in general, but specifically at Unisa, is the main focus of this article. In the study we explored epistemological perspectives from the evolutionary beginnings of humanity as well exploring cybernetic, complex and ecological thinking and discovered new epistemological horizons to view distance learning and student communication. In this philosophical reflection through analytical autoethnography, we grappled with ways to transcend the epistemological split between, on the one hand, our reductionist and mechanistic thinking that requires us to be efficient, and ecological and complex thinking that creates a caring and collaborative ecology. We propose the reclaiming of our humanity by co-evolving all role players in the distance learning context at Unisa into a new culture of learning and communication grounded in passion, curiosity and openness that will enable us to be responsible and participating citizens of the planet.

Key terms: epistemology, ecology of distance learning, autoethnography, analytical autoethnography

\section{INTRODUCTION}

The relationship between the University of South Africa (Unisa) and its students has deteriorated over the past few years. This is evident both from formal research such as the Student Satisfaction Survey $(2012,16)$, but also by simply ‘listening in’ on Unisa’s social media platforms. Although the relationship between the university and distance-learning students is traditionally more distant than at residential universities to begin with, a number of factors have had an influence on the way Unisa relates to students. The merger between Unisa, Technicon SA (TSA) and Vista Vudec (Unisa Annual Report 2003) in 2004 led to rapid student growth 
and a clash of institutional cultures. The consequence was the emergence of a more competitive environment that separated departments into competitive units, which created silos in the organisation. This led to fragmented services and this contributed to alienating students from the university.

In addition, Unisa made a few decisions that contributed to the breakdown in communication, one of which is the closing of the call centre in 2009. Students could no longer call the university and became increasingly frustrated with the inaccessibility of staff. Although the student body grew significantly, the staff component did not, which further led to slow service and a lack of response to student needs.

In the years that followed, various attempts have been made to bring the students and the university closer together or at least to improve student satisfaction. This included improved communication material in both print and digital formats and a new business model that would digitise processes in order for the university to become more efficient in communication and service delivery. All these attempts however seem to have failed and have not improved the relationship between Unisa and its students.

Working in the field of student communication and with students, we felt that exploring student communication in the distance-learning field but specifically at Unisa was an important issue to investigate, especially since very little research has been done so far. When we consulted literature and research around student communication in the distance-learning environment, we found little work on the fundamental aspects of student communication and the relationship between the university in general and the student. Most research focused on a reductionist use of technology and pedagogy in the teaching and learning environment as opposed to a focus on the fundamental human relationship between the university and students (Heydenrych and Prinsloo 2010; Siemens, Gašević and Dawson 2015). Very little was found on how being human is inextricably connected to who we are as humans, how we live, how we communicate and particularly how we learn. This begged the question why and how we learn as humans and how learning and communication should work in the distance learning environment in general but in this case specifically at Unisa.

We decided to pursue a philosophical investigation that included a literature review of the evolutionary beginnings of humanity and humanness where love and collaboration formed the foundations of survival, until the inevitable development of civilisation, competition, science and formal education so that we became alienated from our evolutionary beginnings (Headrick 2009; Maturana and Verden-Zöller 2008; Morin and Kern 1999; Siemens 2006). In an attempt to find an epistemological alternative, we explored, in a second literature review, cybernetics, 
complexity and ecological thinking in order to find new epistemological horizons from which to view student communication in the distance-learning context (Bateson 1988; Maturana and Verden-Zöller 2008; Morin 2008).

Through an intimate reflective struggle using autoethnography (Ellis and Bochner 1996) as research method together with the two literature reviews (Henning 2011), we tried to create a deeper understanding of how to create a vibrant student communication context. From the literature review, we derived some basic fundamental principles for creating a context of living, learning and communication that is truly human. We then used these principles as a map to track our own intimate personal experiences of working at Unisa in the field of student communication using analytical autoethnographic writing (Chang 2008).

What emerged was a process of recursive philosophical reflection through analytical autoethnography. We did this by enriching the basic story of student communication recursively through mapping the theoretical principles onto the context of Unisa's student communication. Then for a second recursive time we reflected on both these stories or combined them in a metareflection or view of the complexity of the issue of student communication at Unisa. The present article describes the process of how this new perspective aided in evolving a proposed framework for how Unisa should relate with itself and its students.

\section{FROM DISTANCE TO DISTANT}

Traditionally, Unisa was a correspondence university, with very fixed processes, support and communication systems. For more than 100 years, the system was characterised by slow and predictable processes and communication was aided by a relatively efficient postal system. Then in the early 1990s, the Internet was invented and South Africa became a democracy. Slowly the environment in which Unisa functioned started to change. Open distance learning became the 'in' thing and Unisa created more support functions for its students. These took the form of extended learning centres, discussion and tutorial classes and online environments.

By the early 2000s, Unisa moved from a year module system to a semester system, which meant that twice as many registrations, assignments and examinations had to be done. There was an increase in the need for support functions in these areas. However, no concomitant increase in staff took place in these support departments.

By mid-2004, through government intervention, Unisa merged with Technicon SA (TSA) and Vista Vudec (Unisa Annual Report 2003). The three organisations had vastly different institutional cultures and people had to fight for positions. Therefore, together with a new bonus-based performance management system introduced in the next decade or so, the merger 
led to the emergence of a competitive culture. Between 2003 and 2013, the resulting strain on administrative and academic systems was exacerbated by the doubling of student numbers in less than a decade.

In 2009, Unisa closed the call centre and implemented a communication system using email and SMS only. After an outcry from students who battled to have their enquiries answered, management gave instructions that all staff had to answer their phones. This was ineffective due to various reasons, but mainly because staff members were overwhelmed by enquires irrelevant to their fields of expertise, which meant that they could not assist students.

It seemed that one of Unisa's mechanisms to cope with the increase in students, administration and complexity was to standardise processes. Methods of communication were chosen, such as mass transmission of SMS text messages, to accommodate the lowest common denominator and this left little room for engaged conversations and communication.

In 2013, the Unisa Council adopted a new Open Distance e-Learning (ODeL) model, which meant that Unisa would become an online university over a relatively short period of time. All students had to be computer literate, own their own digital devices and have good access to the Internet. Unisa's own business processes would also be more automated and there were rumours that the functions of the regional offices would be curtailed.

Unisa started to refer to itself in terms of metaphors of architecture (Unisa's Organizational Architecture: Interim Report 2012) and business, referred to its students as 'clients' or 'customers' and expressed the goal of becoming a high-performance university (Unisa 2013-2015: Towards a High Performance University). The staff members were greatly affected by these changes. Administrators complained about large student numbers and their inability to cope with the bigger workloads. Academics complained about an increase in administrative functions and less time to teach.

Of course, these changes as well as other environmental factors had a great effect on students. While there was less time for them to communicate with the university due to the semester model, the services of the post office slowed down due to strike action and often caused students not to receive study material on time. Students tried to contact the university but no one was answering the phones; and if they did, they could not assist. Students were also now expected to be digitally literate and they had to spend extra money on digital devices and Internet access.

Students turned to social media platforms to voice their frustration, and by 2013, various student protests followed. In September 2013, the vice-chancellor called an assembly to discuss these issues. After a heated debate, a committee was appointed to deal with the issues, and by 
early 2014, Council decided to revert to a blended learning model, namely a model that would accommodate both online and paper-based teaching and learning.

We, the authors, asked ourselves whether this way of decision-making was effective in finding solutions for Unisa's complex problems and whether it was necessary to get to the point of protest action and anger before back-tracking in order to keep the university going. It seemed that even we, the authors, one working in the field of student communication and the other a lecturer, had fallen into the same trap of engaging mostly with problem solving and technology when relating to student communication. We realised that we also forgot about the students and their basic human communication needs and only focused on trying to fix the problem with brochures and websites. It seemed to us that Unisa was no longer a distance learning university but a distant learning university.

\section{THE NEED FOR A NEW PERSPECTIVE}

Our unease with the current state of affairs led us to a new exploration. We decided that we needed new lenses through which to explore student communication at Unisa. Our need was driven by the realisation that there was a lack of thinking about the basic conditions required for living and learning in the distance learning environment at Unisa. When we explored distance learning in the literature, we found that most research and strategic initiatives focused on technology-mediated communication. We could not find research that focused on the ecological conditions required for effective communication in the distance learning university.

Since our own theoretical foundations were grounded in ecological and complexity thinking, we wondered whether exploring Unisa and its own unique context from this perspective would make a contribution. A pivotal moment was that, while reinvestigating our theoretical foundations, we discovered the seminal work of Maturana and Verden-Zöller (2008) called Origins of humanness in the biology of love. This placed us on a path to discover which conditions would be required for us as humans to thrive in a learning environment in general but in the distance learning environment specifically. We decided to explore our humanness on the one hand and ecological and complex thinking on the other, to provide a new perspective on the dilemmas of the distant learning university.

\section{THE PROCESS OF RECURSIVE MAPPING AS METHODOLOGY}

Right from the start we knew that we wanted to explore the issue of student communication at Unisa from a very personal perspective and that a qualitative research approach was needed (Henning 2011, 7). Henning (2011, 7) states about qualitative research, '[t]he researcher is 
unequivocally the main instrument of research and makes meaning ... that she will present as findings'.

Autoethnography fitted our aim perfectly: we could explore the ecology of learning from our own personal experiences and stories and in the process do valid research within the broad constructivist theoretical framework and concomitant ecological, cybernetic and complexity thinking. We laid no claims to the research being objective or generalisable; however, we rigorously followed the analytical autoethnographic methodology in addition to strict philosophical investigation and reflection. This provided in-depth lived experiences as data to explore the context of student communication at Unisa.

We therefore used analytical autoethnography as a research method within the broader framework of a qualitative research approach in the format of a case study design in order to explore student communication in the context of distance learning and specifically in relation to Unisa (Chang 2008). To enhance the analytical autoethnography we used a literature review, document analysis and philosophical reflection to complement our 'story' (LeCompte, Preissle and Tesch 1993).

The aim of the literature review was not only to provide background information for the study, but also to provide the fundamental principles on which the epistemological foundations of the study could be built. We could then map our own stories and experiences to institutional documents and the theoretical fundamentals (Jones, Adams and Ellis 2013, 33).

The process can therefore be described as a recursive process of philosophical reflection through analytical autoethnography, and can be diagrammatically represented in Figure 1.

The diagram shows the process followed by the primary researcher in her research journey where she reflected on her view of Unisa three times recursively. She wove her perspective of Unisa's context of student communication each time into meta-levels of reflection enriched by the literature and emergent levels of reflection.

The first reflection told the story of the researcher's personal view of her lived experience of how Unisa dealt with student communication and her role in it in an autoethnographic format. The second reflection explored stories of the primary researcher's lived experiences of Unisa, but this time using a new epistemological lens coloured by the theoretical framework where she distilled seven fundamentals of human, ecological and complex thinking from the literature review.

The third reflection combined these two previous reflections and provided some conclusions and recommendations, which could lead to a new framework for student communication at Unisa. 


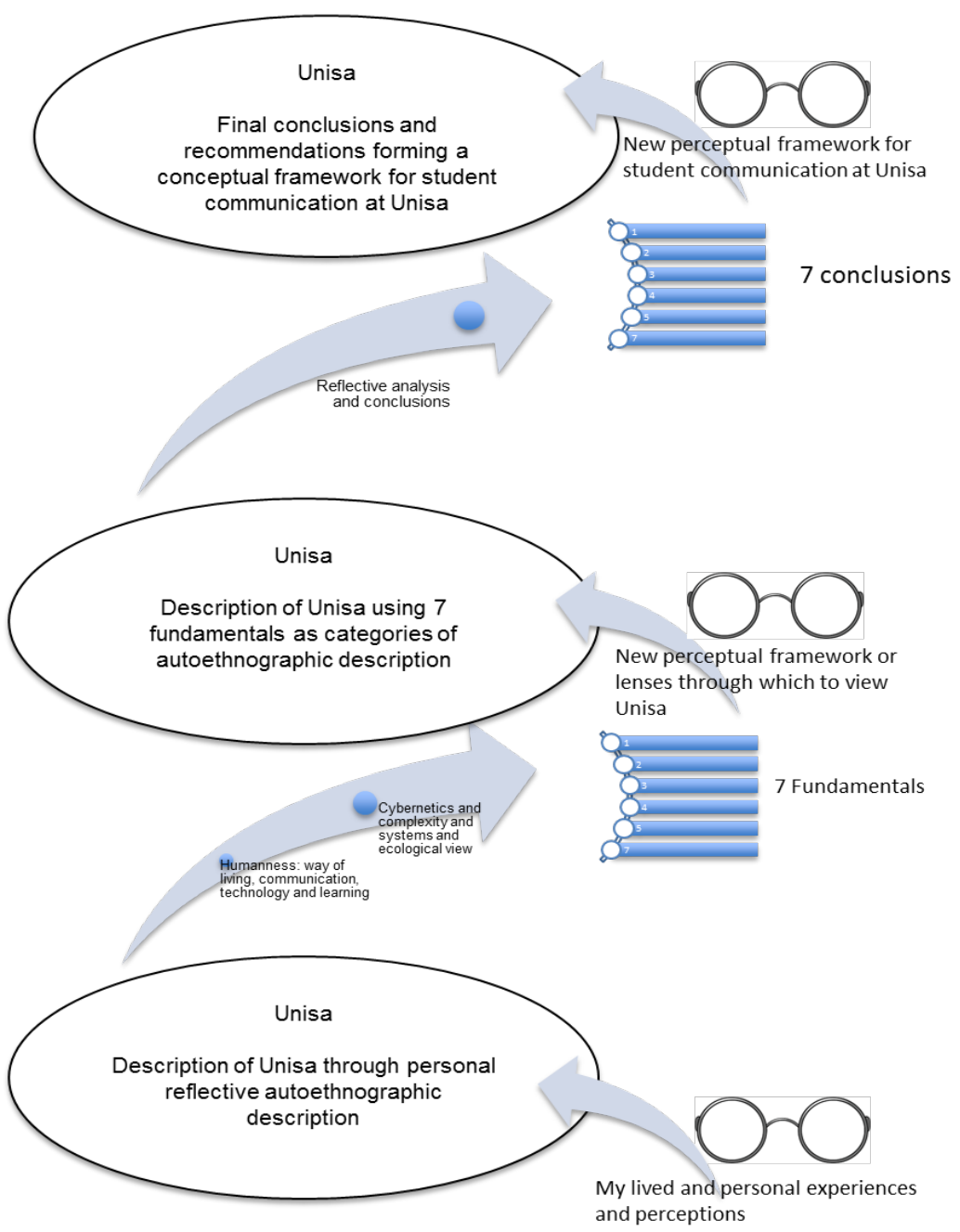

Figure 1: Recursive process of philosophical reflection through analytical autoethnography

\section{SEVEN FUNDAMENTAL PRINCIPLES OF HUMANNESS, ECOLOGY AND COMPLEX THINKING}

In our attempt to find answers we embarked on two extensive literature reviews. Firstly, we explored humanness, and specifically how we, as a species, became who we are. We followed human evolution through four phases from our early evolution and an organic way of living to becoming a species that started to control our environment and created civilisations and then started to conquer the world and lastly spread across the globe and developed communication systems that connected us on a planetary scale (Maturana and Verden-Zöller 2008).

Secondly, we explored a new epistemological vision for how to deal with student communication at Unisa. We started with cybernetics and second-order cybernetics and further explored complexity and complex thinking. We focused on the works of Bateson (1988; 1991; 2000), Maturana (Maturana and Varela 1980; 1992; Maturana, and Verden-Zöller 2008), Capra 
(1983; 1988; 1992; 1997; 2001), Kauffman (1993; 2008), Morin (1999; 2008) and Cilliers (2000; 2005; 2007) amongst others. These scientists reject the mechanistic reductionist epistemology and view life from a complex, holistic, ecological and systemic point of view that provides new ways of looking at the world.

After a process of rigorous distillation, we derived seven principles of human, ecological and complex thinking from the literature review. These principles are:

- A new epistemological vision for Unisa: from reductionism to an ecology of ideas. Reductionist thinking creates an environment and metaphors that are mechanistic and rigid. Ecological thinking, however, proposes an epistemology of life, vibrancy, interconnectedness and complexity (Bateson 1988, 246).

- A holistic and holographic perspective of Unisa. The idea that the whole is more than the sum of its parts implies that one gets a meta-view, or steps back to see the bigger picture. Bateson (2000, 267) says, 'The whole is always in a meta-relationship with its parts' which means that no part of any system can be viewed as parts alone. The holographic perspectives take it one step further where the whole and the parts of any system reflect one another but that each part also retains its uniqueness (Morin 2008, 84-89).

- Unisa as a living system. Life and all mind is the pattern that connects, which needs interaction between its components, triggered by difference, containing collateral energy, requiring circular chains of determination in which information is transformed or coded in logical levels (Bateson 1988). It is a complex dance of circular feedback and causation that evolves patterns of self-organisation but requires energy. This recursive selforganisation has three functions. It simultaneously creates the system, determines the autonomy of the system and makes the system closed to information. In living systems there are no 'happenings', only 'doings', which means that everything is part of the dance of life, created somehow between the patterns that connect it (Kauffman 2008, 85). Behaviour in complex living systems is not predictable (McMillan 2008, 42). Complex living systems have a memory that determines how they assimilate change and therefore change can only happen at the pace a system itself can determine (Cilliers 2000, 23-24). The natural pattern of living systems is networks, and networks are not hierarchical but systems nested in systems (Capra 1997, 35).

- $\quad$ Co-evolution and change - in complex systems change cannot be introduced but is a coevolutionary process, since the organism and the medium change together. Change is a delicate balance between change and stability based on the organisation of the system 
(Keeney 1983, 68). Since the behaviour of complex systems is unpredictable, facilitating change is difficult. However, patterns do emerge and often create greater states of complexity. Chaos and change are often related and change often happens at the edge of chaos (Kauffman 1993, 323). Because complex systems are sensitive to initial conditions, the timing when change is introduced is also very important (Gleick 1987, 8).

- $\quad$ Our essential humanness. Humans evolved in small intimate communities within a context of cooperation, interdependence and love where story-telling and doing things together towards a common goal were part of the prevailing culture (Maturana and Verden-Zöller 2008). According to Maturana and Verden-Zöller (2008, 30-33) we thrive and need loving communities to be happy. Through recursive reflection by means of languaging and emotioning which Maturana and Verden-Zöller (2008, 30-33) use as active verbs to indicate that they are co-evolving and dynamic processes, create meaning in life and domains of inter-objectivity/subjectivity. We live a life of patterns and stories using a complex process of both digital and analogue communication to create rich communication and culture (Bateson 2000, 128-138, 280-308, 365-399). Humans therefore function optimally in a context of care, love and respect where they are not viewed as objects but as subjects. Creating a context of respect, cooperation and intimacy and valuing the sacredness of life will provide us with an optimal space to live and learn.

- Learning in a complex world. As humans, we learn best in a context where there is a sense of place with a culture based on respect and close intimate relationships and where the uniqueness of the student is treasured and passion is encouraged. In such a context, learning should be relevant to the needs, passion and life circumstances of the student. Effective learning is also a co-evolutionary process that happens in self-organised networks of connectedness between various levels of networks using the technology in the network society (Morin and Kern 1999). Learning also happens across various logical levels where learning to learn creates deeper learning (Bateson 2000, 283-306). This happens through conversation to create meaning and where the teacher is the learner and the learner is the teacher. Technology can form part of such a process of self-organised learning by opening channels of human communication and mutual encouragement. New learning models require new academic thinking about openness, transparency, diversity and flattening of hierarchies that will allow the redistribution of decisions and openness to new ways of looking at science and the world (Siemens 2006, 29). We therefore need a complex perspective on education which includes understanding the philosophy of knowing, integration of subjects in a holistic context, understanding the human condition 
and an earth identity as well as confronting uncertainties through a process of learning to understand each other and a new planetary ethics (Morin 1999, 39).

- Complex thinking and the ecology of action. Complex systems have a memory and need time to reflect on the change and stability, and the co-evolutionary process cannot be closely mapped into the future (Morin 2008, 96-97). Such thinking requires a culture that will have to learn to live with uncertainty because the future cannot be planned and predicted. A new strategy will have to include ways to develop a culture of creativity and openness in thinking, where opposing ideas are embraced and where common patterns are found that will lead to new paths of change.

These ideas may seem idealistic, or even naïve, but they are reflected in new scientific thinking that is emerging in the work of Morin (2008), Maturana and Verden-Zöller (2008), Kauffman (2008), and Capra (1983; 1992; 2001). It seems that through rigorous reflective scientific endeavours and philosophy some scientists have made the discovery that if we return to our human roots, founded in respect for the sacredness of life, which is found in connectedness, collaboration, love, co-operation, intimacy and the wholeness of the universe, a new science can be born.

Both Kauffman (2008) and Bateson (1991) say that we must find sacredness again. Although it is traditionally referred to in the religious domain, they extend it into the human consciousness and said that the sacred is the space between us, and that a prosperous future can only be found if we find the sacred space between us through conscious awareness of the importance of our relationships with one another. Morin and Kern (1999) essentially say the same by calling for fellowship between humanity in order for everyone to work together on a better future. Such a space requires a culture of respect, collaboration and openness to have differing opinions.

\section{AUTOETHNOGRAPHICAL REFLECTIONS}

In the study and the process of autoethnographical reflection, the primary researcher in her first reflection of Unisa started to tell her story of her personal relationship with the university and how it evolved. She reflected on how, while she was working in a mental hospital more than 20 years ago, she discovered the writings of Gregory Bateson who, in his cybernetic and ecological thinking opposed the medical model of the mental hospital. This led the researcher to do a Master's programme at Unisa and later started to work for the university. During the more than 20 years of working at Unisa she formed part of a team who worked on improving 
student communication. All the attempts to improve student communication failed and during the study we felt that we needed a new second order view of Unisa.

In the second order reflection, we combined storytelling with the 7 theoretical fundamental principles derived from the literature reviews. In this article we are unable to share most of the reflections, but will mention only a few to show how the process of second order reflection worked and contributed to the study.

One such reflection was the story of a staff assembly that took place around the time of turmoil in 2013 where, management, academics, administrators, unions and students discussed the new business model. The different parts of the organisation had very different views on how the future vision should be implemented and this revealed a pattern of disconnect and distantness, where the wholeness is not valued and respected. This lead to our reflection on the holographic principle of complex systems where all parts of the organization are reflections of one another and if one respected this view, more complex and innovative patterns can evolve.

Another story was a very personal reflection with one of the academics at Unisa and how he felt alienated from the organizational ethos with its one size fits solution to most problems. This new ethos made him feel that he could no longer be creative or contribute to the organisation, which in his mind further perpetuated the culture of disconnect. The lecturer felt that this had a significant impact on the pace and manner in which both staff and students performed. We reflected that Unisa became a very mechanistic and stagnant organization where change is imposed from the top and where human creativity and living elements in the organization were stifled. If, however Unisa were viewed as a living system, individual creativity would not only be allowed but valued.

The last story we will mention here, was is a very personal reflection of the primary researcher and her personal experience of studying through distance learning when she did a short course at Unisa. She compared that experience to doing a Masters' Programme where she had a lot of personal interaction with Unisa lecturers. During the second order reflection the researcher contemplated ways in which Unisa could embrace complex thinking and embrace self-organization in the relationship between the student and the university.

These second order reflective stories provided a very rich set of data that assisted the researchers in finding new ways of viewing a university in the complex networked world we live in. This helped to chart a way forward in which we could find a new journey away from a mechanistic and corporatized environment to one that is human, creative, collaborative and conducive to learning in the complex world. 


\section{DISCUSSION AND RECOMMENDATIONS}

During the process of autoethnographic recursive reflection, we realised that Unisa is functioning much like a machine with strict step-by-step processes and also much like a business which is ruled by financial models. In this new environment at Unisa, reductionist and mechanistic thinking has become the way we deal with issues in general but also with decisionmaking around the way we communicate with our students. If, however, we view Unisa as a living organisation deeply rooted in humanness, we will deal with student communication in a very different way.

Although Unisa is by law a hierarchical institution, we can view Unisa as a living system and community that can create an environment of caring and collaboration. In a living system, the structure may be viewed as nested systems where the systems are within systems or one system is the context for another system and there is no one above or below; a system that has a sense of place and a caring and collaborative community. This will require the creation of an ethos that will guide us to more openness and self-organisation, where spontaneous initiatives are welcomed, where new contexts are created to find common solutions and where it is possible to find new innovative ways to create an ecology of distance learning.

In order to create an ecology of learning we need a new epistemological and cultural foundation, one where we value the student and all members of staff as part of the ecology and where everyone can make a contribution to the co-evolution of the ecology. This foundation would create a place where learning is our first priority, but not top-down learning, rather colearning and learning about learning so that students can go into the world knowing how to deal with life and have the ability to participate in personal, local and global issues.

This will entail encouraging the formation of learning networks using technology in the network society where Unisa can embrace various platforms, whether face to face or technology-enabled to create collective meaning making as a collective ethos. This collective ethos should however be part of the co-evolution of the context of the learning network and should not be imposed on the entire staff and student body. It should evolve in a flexible manner so that students can participate in conversations where their own preferred platforms of communication can co-evolve.

As opposed to our current top-down hierarchical learning with fixed outcomes, the new self-organised learning ethos would require a radical new way of thinking by lecturers, tutors, communications officers, mentors and even students and alumni, where open communication and open thinking are encouraged using face-to-face and technology-mediated communication, where the ability to see a pattern, meaning making, awareness of process and openness to be 
involved in networks and their changing nature are understood. This requires a culture where the lecturer is not the only expert and where openness means that you recombine ideas and form new ideas by rigorous scientific and creative, emotive 'thinking' and where assessment is not only about writing an assignment or examination but looking at the individual's ability to think and apply learning in a wider context of living and learning. Cross-subject discussions should be welcomed and lecturers will have to broaden their interest beyond the subjects that they teach.

In a new culture of openness and respect, change should not be imposed on the organisation but should co-evolve in the system. A new culture based on ecology will have a sense of tolerance for each other and patience and openness to allow the emergence of new ways of being. Co-evolution requires adequate time and space to reflect recursively on the issues at hand. We therefore need to have patience and allow the pace of the system to dictate the pace of change and not force change in a hurried manner. It is necessary to have an understanding that change cannot happen either too slowly or too fast and that we cannot exactly predict how these changes will play themselves out.

Many more solutions (including technology) will be welcomed as long as they aid the learning process. In such a context, communication would not have central control mechanisms but we will encourage self-organised groups among students, the public, lecturers, administrators, alumni, and anyone who wants to be part of the ecology. In a co-evolutionary process, the students can participate in creating such contexts for learning that will allow open collaboration and co-evolution of learning.

A new strategy for Unisa's student communication will have to be a co-evolutionary process where new solutions for distance learning can emerge in order to bridge the distance through passion and dedication and where technology can be used in order for Unisa to no longer to be a distant learning university.

The strategy must include a common vision grounded in passion and an emotional connection between Unisa and its students and the process of learning. This will empower us to find our humanness and see how what we do and learn affect our earth identity and our own survival on the planet.

The most profound affect however, we believe, is at epistemological level. This new way of dealing with student communication requires a total change in thinking, not only about student communication but also about who Unisa is in its fundamental epistemology. It seems that Unisa must make an epistemological choice. The change is not a choice between either efficiency and caring, but the choice of which one to put first, which one to make part of its 
essential epistemological self, which will influence decision-making and policy. If we make the choice to view Unisa first from an ecological epistemology and focus on being and creating a caring, empowering and connected culture we will allow both staff and students to be creative and connected and this in turn will enhance our efficiency through passionate engagement.

However, this is not just a simple individual or collective choice. Understanding Unisa from a more holistic or even holographic perspective as defined by Morin (2008) will help us to face ourselves. Morin (2008, 88-89) defines the holographic principle as the idea that parts and wholes are complementary in that the whole is also reflected in the parts, much like the DNA of an organism contains all the information about the whole.

Through the autoethnographic reflection we realised that we are Unisa and Unisa is us. We are not separate; we are holographic reflections of each other. Together we must all create a new culture where the parts stop blaming each other for decisions and mistakes, but where we embrace each other with our abilities and shortcomings and where the whole is in synergy and reflects the same values of respect for the wholeness and all its parts. Such a new perspective requires the creation of a culture where the focus is on interdependence and interconnectedness as well as respect and understanding, care and collaboration through which we can create a new ecology of distance learning that focuses on building a learning ecology where everyone participates in creating such an ecology that is no longer distant.

So the question is, where do we start? We start with ourselves, each one of us through self-reflection, realising that we are not separate; we are connected, all of us: staff, lecturers, students and management. Only we can create this ecology and we can co-evolve the change. We need to break down the barriers between us, and bridge the distance between the university and students and create a new ecology of learning, one that is connected, caring and engaged, and we need to act together as citizens of our university, our communities, our countries but also our planet.

In practical terms we propose a personal strategy where we no longer view ourselves separate from Unisa. We are holographic reflections of Unisa and practical solutions require us to reflect both inward and outward to find practical solutions. We therefore felt that could not present Unisa with a 'complete solution' but we could actively participate in the ecology both at Unisa, in our broader social relationships and also in the global ecology of learning.

Looking inward, we can, in our working in the field of student communication at Unisa, create opportunities to bring as many people in the organization together to co-evolve a new student communication strategy. Collectively we can influence the organization in practical ways through the use of social media where we can start the conversation where others might 
want to participate. It requires openness and respect, and the ability to listen to the conversations and create recursive conversations where the more opinions there are the more the complexity will appear and in the process, new ideas will co-evolve and more complex patterns will emerge.

Another idea might be to start with a pilot project such as a pre-registration programme, involving academics, students, CMO's, tutors and administrators to create conversations about how to participate effectively in the Open Distance Learning space. One where it is not just a lecturer standing in front of a class but people sharing ideas and co-evolving networks of conversation. We can also help students to create networks of conversation around themselves that will stimulate conversation regarding their own area of interest and will also give them a wider view of academic issues. This process might be a slow co-evolving process where the network can self-organise into more complex networks of collaboration. Creating a strategy and policy that encourages active conversations with students will also create greater participation in the organisation regarding the issues, where the conversations will co-evolve into a new culture of participation and collaboration, rather than a culture of aggression, frustration and completion.

Looking outward, we can explore how the world is more and more connected, where learning is no longer the sole domain of universities, and the Internet has opened up possibilities of learning outside formal structures, most distance learning universities will have to find new and innovative ways to both communicate with students and find ways of learning that is more relevant to the way people are living in the network society today.

In real terms the breakdown of the knowledge hierarchy can be a real economic threat to universities. With the increased corporatization of universities on the one hand and the network society where knowledge is open on the other way, we must find new ways to 'be' universities. We therefore do not propose that individual university hierarchies should collapse, but they can be viewed in a different light. Thus the holographic principle implies that complex living systems do not thrive in rigid hierarchies, but they co-evolve in a symbiotic way. The hierarchy and the network can co-evolve into nested systems where respect for both is maintained.

We propose that distance-learning universities start to move their focus away from issues of how technology can enhance student communication but focus on epistemological issues. This will place the student at the centre and technology and efficiencies will then be the outcome of a co-evolutionary process for the ecology of learning.

Creating ecologies of learning where open interaction is encouraged, where there is no real central node of control, where the teacher is a facilitator and no longer the only source of 
knowledge and where collaboration is the main way of being, can change society fundamentally. In this complex global networked world where equality and the individual has again become valued, and learning is the right of everyone we must find new ways to live, communicate and learn, find new ways of becoming institutions of learning. Such new ways of thinking will make us value each other, value each individual's place in this world, value our environment and the planet we live in, but always find new ways of learning facilitated by technology that will allow us to self-organise into communities of learning. In such communities we will learn about life and knowing as we live it and possibly find solutions to our social, emotional, organisational and planetary problems. Publishing this article is one small way of doing this.

\section{CONCLUSION}

For more than a century, Unisa has created a context for learning for many in South African society. In the last few decades, however, both external and internal factors have created a distance between the student and the university. Factors such as the merger, a marked growth in student numbers and decisions such as the closing of the call centre created a sense of disconnect between the student and the university.

Our own discomfort with the situation led us to undertake the study reported here in order to explore student communication at Unisa by finding new epistemological horizons. What coevolved was a process of recursive philosophical reflection through analytical autoethnography. The primary researcher used a reflective process in her research journey where she reflected recursively on her view of Unisa three times. Each time she wove her perspective of Unisa's context of student communication into meta-levels of reflection enriched by the literature and emergent levels of reflection.

This process of literature review and recursive reflection led us to distil seven fundamental principles based on ecological and complex thinking that helped in the process of reflection. It helped to explore new ways of thinking and being a university in order to bring us closer to our students and to define a relationship and create a culture to co-evolve new solutions for learning and communication.

What we discovered was that Unisa needs to co-evolve a new culture that embraces the university as a living system, based on humanness. As humans, we need cooperative and caring environments to thrive and learn effectively. Therefore, in the planetary age as defined by Morin $(2008,84)$ as the age where everything on the planet is connected or otherwise defined as the network society we need to embrace a new way of learning. Open networked and self-organised 
learning embrace the network society and can be used to bring the university and the student closer together. Together we can then co-evolve new solutions for learning, and communication and develop strategies that can solve our institutional dilemmas.

In such a culture, we will not separate ourselves from each other but rather view ourselves and each other, students and staff, as holographic reflections that will help all of us see that together we can create a culture of cooperation, caring and open learning. In this culture, we will break down the hierarchical structures that separate us and rather form networks of communication. Such a culture will be collaborative and will not only enable us to become part of a true ecology of learning, but also enable our students to be responsible and participatory citizens of the university but also of their communities and our planet.

Alvin Toffler (in Greenstein 2012, 139) says, 'The illiterate of the 21st century will not be those who cannot read and write, but those who cannot learn, unlearn, and relearn'. The crisis we are facing is not one of technology or sustainability or e-learning. Our real crisis is one of our students not learning how to learn, live and love in both their local but also planetary or global society.

It will however require an epistemological shift and that is not easy, but it must begin with each one of us. We must realise that we can no longer find simple solutions to complex problems. We need each other, because it is only together that we can co-evolve strategies that will connect us through active collaboration, caring and a love for learning. Then we can find the sacred space between us from which to co-evolve new ways of learning and create a true ecology of learning.

It seems we no longer have a choice but to allow ourselves to co-evolve a new culture that is passionate about education and learning. This time, however, it needs to be a new kind of learning; a learning that is passionate about lifelong learning and a learning that will make us all responsible and participating citizens of this most beautiful planet.

\section{REFERENCES}

Bateson, G. 1988. Mind and nature: A necessary unity. New York: Dutton.

Bateson, G. 1991. A sacred unity: Further steps to an ecology of mind, ed. R. E. Donaldson. New York: Cornelia \& Michael Bessie Book.

Bateson, G. 2000. Steps to an ecology of mind: Collected essays in anthropology, psychiatry, evolution, and epistemology. Chicago: University of Chicago Press.

Capra, F. 1983. The turning point: Science, society and the rising culture. New York: Simon and Shuster, Bantam Book.

Capra, F. 1988. Uncommon wisdom: Conversations with remarkable people. London: Flamingo.

Capra, F. 1992. The Tao of physics: An exploration of the parallels between modern physics and eastern mysticism. Berkeley: Shambhala Publications. 
Capra, F. 1997. The web of life: A new synthesis of mind and matter. London: Flamingo, Harper Collins. Capra, F. 2001. The hidden connections: A science for sustainable living. London: Flamingo.

Chang, H. 2008. Autoethnography as method. Walnut Creek, CA: Left Coast Press.

Cilliers, P. 2000. What can we learn from a theory of complexity? Emergence 2(1): 23-33.

Cilliers, P. 2005. Complexity, deconstruction and relativism. Theory, Culture and Society 22(5): 255267.

Cilliers, P. 2007. On the importance of a certain slowness. Stability, memory and hysteresis in complex systems. In Worldviews, science and us: Philosophy and complexity, ed. C. Gershenson, D. Aerts and B. Edmons, 53-80.

Ellis, C. and A. P. Bochner, eds. 1996. Composing ethnography: Alternative forms of qualitative writing. United States of America: Rowman Altamira. (Kindle Edition).

Gleick, J. 1987. Chaos: Making a new science. New York: Viking.

Greenstein, L. 2012. Assessing 21st century skills: A guide to evaluating mastery and authentic learning. Thousand Oaks, California: Corwin.

Headrick, D. R. 2009. Technology: A world history, 54-56. New York: Oxford University Press.

Henning, E. 2011. Finding your way in qualitative research. Pretoria: Van Schaik Publishers.

Heydenrych, J. F. and P. Prinsloo. 2010. Revisiting the five generations of distance education: Quo vadis? Progressio 32(1): 5-26.

Jones, S. H., T. E. Adams and C. Ellis. 2013. Handbook of autoethnography. Walnut Creek California: Left Coast Press Inc.

Kauffman, S. A. 1993. The origins of order: Self-organization and selection in evolution. New York: Oxford University Press.

Kauffman, S. A. 2008. Reinventing the sacred. A new view of science, reason, and the sacred. New York: Basic Books.

Keeney, B. P. 1983. Aesthetics of change. New York: Guilford Press.

LeCompte, M. D., J. Preissle and R. Tesch. 1993. Ethnography and qualitative design in educational research. San Diego, CA: Academic Press, Inc.

Maturana, H. R. and G. Verden-Zöller. 2008. The origin of humanness in the biology of love, ed. P. Bunnell. Exeter, UK: Imprint Academic.

Maturana, H. R. and F. J. Varela. 1980. Autopoiesis and cognition: The realization of the living. Dordrecht: Reidel.

Maturana, H. R. and F. J. Varela. 1992. The tree of knowledge: The biological roots of human understanding. Revised edition. Boston: Shambhala.

McMillan, E. 2008. Complexity, management and the dynamics of change: Challenges for practice. New York: Routledge.

Morin, E. 1999. Seven complex lessons for the future. Paris: Unesco Publishing.

Morin, E. 2008. On complexity. Hampton Press.

Morin, E., and A. B. Kern. 1999. Homeland EARTH: A manifesto for the new millennium (Advances in systems theory, complexity and the human sciences). New Jersey: Hampton Press.

Siemens, G. 2006. Knowing knowledge. Lulu. com. A Creative Commons License. http://www.elearnspace.org/KnowingKnowledge_LowRes.pdf (accessed 6 January 2013).

Siemens, G., D. Gašević and S. Dawson. 2015. Preparing for the digital university: A review of the history and current state of distance, blended, and online learning. A Creative Commons License. linkresearchlab.org/PreparingDigitalUniversity.pdf (accessed 24 November 2015). 


\section{Unisa documents}

Student Satisfaction Survey. 2012: 16.

Unisa Annual Report. 2003.

Unisa’s Organizational Architecture: Interim Report. 2012.

Unisa 2013-2015. Towards a High Performance University. 